\title{
Circulation Journal Worldwide
}

Hiroaki Shimokawa, MD, $\mathrm{PhD}$

Dear Colleagues,

On behalf of the editorial team of the Circulation Journal, the official journal of the Japanese Circulation Society (JCS), I am pleased to report that the scientific and internationalization levels of the Journal are steadily increasing. The JCS should represent not only Japan but also countries in the Asia-Pacific region, which would position the Circulation Journal in our region as equivalent to that of Circulation, published by the American Heart Association (AHA), in America and the European Heart Journal, published by the European Society of Cardiology (ESC), in Europe (Figure 1). Indeed, the goal of the editorial team is to continue to enhance the scientific and internationalization levels of the Circulation Journal.

\section{The Official 2011 Impact Factor}

The Circulation Journal has earned an official 2011 impact factor (IF) of 3.766, which places the Journal 25 among the 117 journals in the Cardiac \& Cardiovascular Systems category, one of the most competitive categories, in the 2011 JCR Science Edition (Figure 1).

\section{International Editorial Team}

The editorial team of the Circulation Journal consists of 34 Japanese associate editors, 80 Japanese editorial board members, 16 international associate editors, and 27 international advisory board members. All the international associate editors and advisory board members are internationally recognized cardiovascular researchers, substantially contributing to the enhancing of the Journal's scientific and internationalization levels. I deeply appreciate their valuable contribution to the Journal.

\section{International Editorial Board Meeting}

The $3^{\text {rd }}$ International Editorial Board Meeting was held in Los Angeles on November 5 during the 2012 AHA Annual Scientific Meeting. A total of 38 Japanese and international associate editors attended and exchanged

\section{Circulation Journal Worldwide}

Figure 1. Circulation Journal, the official journal of the Japanese Circulation Society (JCS), should represent the Asia-Pacific region, similar to Circulation, published by the American Heart Association (AHA), in America and the European Heart Journal, published by the European Society of Cardiology (ESC), in Europe. Numbers in parentheses show the 2011 impact factor of each journal. 

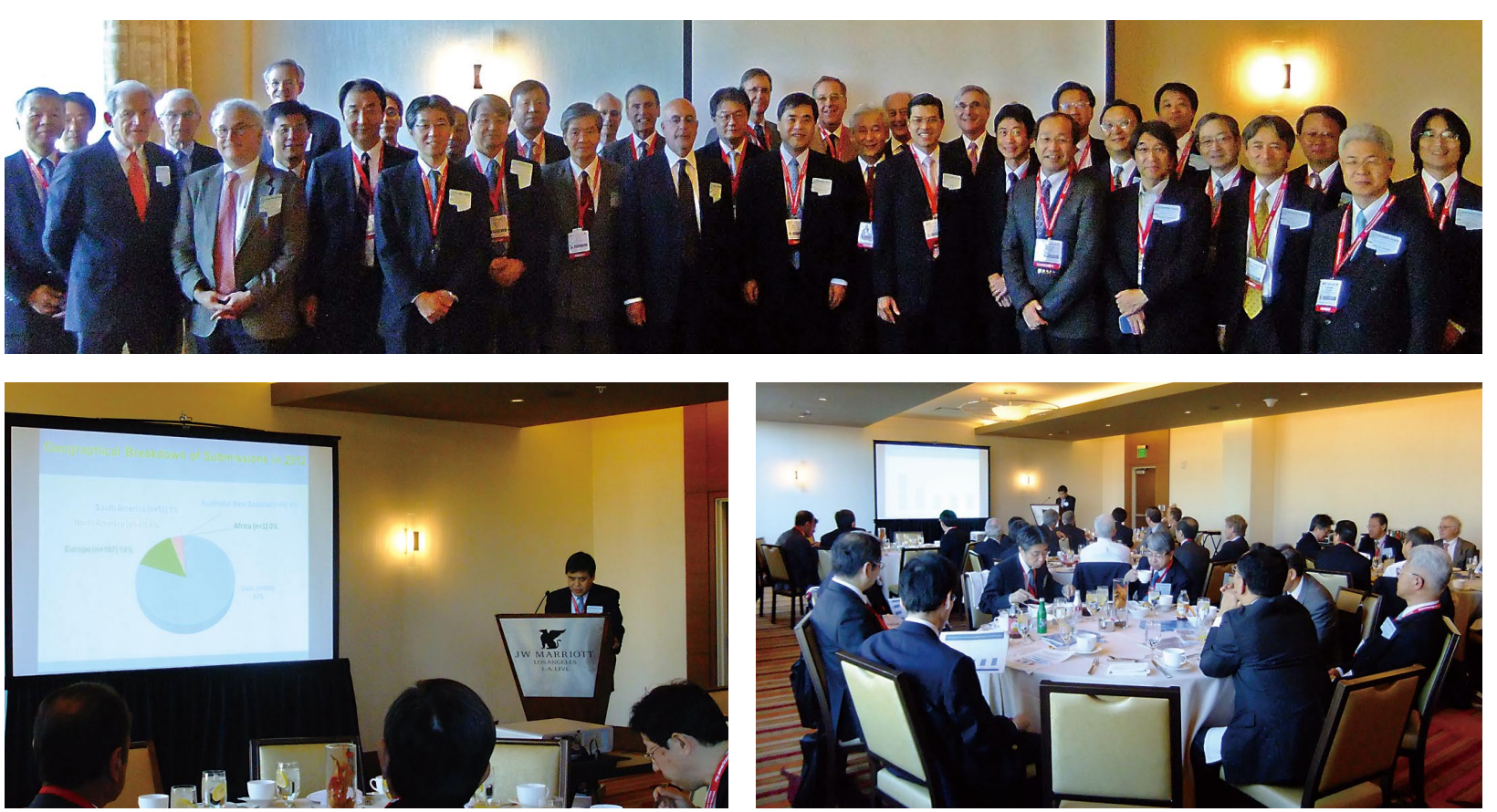

Figure 2. For the $3^{\text {rd }}$ International Editorial Meeting of the Circulation Journal, a total of 38 Japanese and foreign associate editors attended and exchanged opinions on how to enhance the scientific and internationalization levels of the Journal. The meeting was very successful. Please visit the homepage of the JCS (http://www.j-circ.or.jp/english).

opinions on how to enhance the scientific and internationalization levels of the Journal (Figure 2). The meeting was very successful, as many valuable opinions were exchanged in a friendly atmosphere, and I was convinced that the internationalization level of the Journal is truly being enhanced.

4. Review Series by Internationally Recognized Cardiovascular Scientists

I am pleased to report that for 2013, a total of 65 leading cardiovascular scientists have kindly agreed to write review articles for the Circulation Journal. I appreciate their valuable contribution to the Journal.

\section{New Series on Cardiovascular Epidemiology in Asia}

Based on the discussion during the $3^{\text {rd }}$ International Editorial Board Meeting, we will publish a new series on cardiovascular epidemiology in Asia, including overview, ischemic heart disease \& stroke, heart failure, arrhythmias, and hypertension \& life-style-related diseases, from the July issue of the Journal.

\section{International Information Service}

In addition to the free on-line journal system with J-Stage, we provide an international e-mail service to inform approximately 6,000 foreign cardiovascular researchers of the contents of the current issue of the Journal each month.

\section{Representation at the Annual Scientific Meetings of Major Foreign Cardiovascular Societies}

Each year, during the annual scientific meeting of the major foreign cardiovascular societies, such as AHA, ACC, and ESC, the JCS has a booth where information about the Circulation Journal is provided to foreign attendees.

Our International Editorial Team would highly appreciate your continuous support and contribution to the Circulation Journal in our endeavor to enhance the scientific and internationalization levels of the Journal. 